\title{
ANALISIS BAHASA INGGRIS DAN PEDAGOGIS NOVEL TEEN LIT SEBAGAI BAHAN PENDAMPING MATA KULIAH TRANSLATING DAN LITERATURE
}

\author{
${ }^{1}$ Cynantia Rachmijati, ${ }^{2}$ Anita Anggraeni \\ ${ }^{1,2}$ STKIP Siliwangi
}

\begin{abstract}
ABSTRAK
Novel teenlit merupakan sebutan untuk genre novel remaja. Teenlit berasal dari kata "teen" yang berarti remaja dan "lit" yang diambil kata literature yang berarti tulisan atau karya tulis. Novel teenlit berarti tulisan atau karya tulis yang dibuat untuk remaja dan isinya pun menceritakan kehidupan remaja.Penelitian ini yang berjudul "Analisis bahasa Inggris dan pedagogis novel teen lit sebagai bahan pendamping mata kuliah translating dan literature" bertujuan untuk mengetahui jumlah dan tipe campur kode kata dalam novel teen lit serta mengetahui aspek pedagogis apa saja yang terdapat pada novel ini. Subjek penelitian ini adalah novel genre chick-lit : "Aviredie" karya Alline , "Grow up!" karya Sucia Ramadhani , "Pertama kalinya!" karya Sitta Karina dkk dan "Oppa and I" karya Orizuka dan Lia Indra. Serta novel genre lad-lit : "Hidden agenda" karya Jacob Julian, "Marmut merah jambu" karya Raditya Dika , "School of Chemistry” karya Al Dhimas. Metode penelitian adalah pendekatan kualitatif. Hasil penelitian menunjukkan bahwa umumnya teen-lit tersebut mengandung lebih banyak ungkapan outer code mixing(Bahasa Inggris) dibandingkan dengan inner code mixing(Bahasa Indonesia informal), serta umumnya mengandung aspek pedagogis yaitu sosial, budaya dan moral. Ungkapan inner code mixing lebih sedikit ditemukan, demikian juga dengan aspek pedagogis dalam bentuk moral. Novel yang paling banyak mengandung ungkapan dalam bahasa Inggris adalah novel "School Chemistry" dan "Pertama kalinya!". Bagi para pendidik terutama guru Bahasa Inggris, bisa menggunakan novel teen-lit ini sebagai salah satu bahan ajar namun sebaiknya penggunaannya didampingi agar manfaatnya lebih positif dan penggunaan ungkapan bahasa Inggrisnya lebih efektif.
\end{abstract}

Kata kunci : analisis, bahasa Inggris,aspek pedagogis, teen lit

\section{PENDAHULUAN}

\section{A. Latar Belakang}

"Teen Lit" atau "teen literature" adalah kisah novel remaja yang terkenal mulai tahun 2000-an. Novel Teen Lit pertama yang keluar pada awal tahun 2000-an adalah novel "DeaLova" yang laris terjual sebanyak 10.000 eksemplar. Karena kisahnya yang cenderung ringan dan terkadang terkesan hedonis, menimbulkan banyak pertentangan antara pembacanya dan para pengamat. Meskipun teen-lit dan chick-lit tidak selalu hanya dibaca oleh pembaca usia remaja saja, namun banyak pengamat sastra mengatakan bahwa teenlit adalah karya sastra rendah dan tidak berbobot

(http://www.binasyifa.com/279/51/27/feno mena-buku-novel-remaja-teenlit.htm).

Dalam teen-lit juga, cukup banyak campur kode kata antara bahasa Indonesia dan bahasa Inggris yang terdapat didalamnya yang dimaksudkan agar sesuai dengan konteks bahasa remaja. Contohnya yang terdapat dalam novel "Imajinatta" karya Mia Arsjad berikut ini :"Siapa tahu kali ini dreams come true !", "Kamu udah tahu namaku kan?"jawabnya sok flirting. Ujaran dalam dialog dan narasi yang 
terdapat dalam novel teen-lit yang banyak diselipi oleh campur kode kata ini menarik untuk diteliti. Ditambah lagi, kandungan teen-lit yang erat kaitannya dengan kehidupan remaja dapat bermanfaat sebagai bahan ajar di kelas dan mengenalkan remaja kepada kehidupan. Melalui jalinan cerita yang ada, pembaca (remaja) disuguhi berbagai persoalan serta bagaimana tokoh-tokoh yang ada dalam cerita berupaya mengatasi berbagai persoalan yang dihadapinya. Dari sini, secara tidak langsung remaja mengenal berbagai masalah remaja sekaligus belajar mengatasinya. Bahkan, dalam novel-novel remaja tersebut sering pula ditemukan halhal yang sangat inspiratif dan sangat kuat dalam memberikan motivasi bagi pembacanya.

\section{B. Tujuan Penelitian}

Tujuan dari penelitian ini adalah :

1. Mengetahui jumlah dan tipe campur kode kata dalam novel teen lit

2. Mengetahui aspek pedagogis yang terdapat pada novel teen lit

\section{Ruang lingkup penelitian}

Ruang lingkup penelitian ini adalah sebagai berikut:

a. Subyek penelitian adalah novel teen lit yaitu yang terdiri atas :

1) Novel chick-lit

2) Novel lad-lit

b. Menganalisa kalimat bahasa Inggris dalam novel tersebut berdasarkan teori Suwito(1985)

c. Nilai-nilai pendidikan dalam novel sebagai berikut (Andika,2010): nilai pendidikan religius, nilai pendidikan moral, nilai pendidikan sosial serta nilai pendidikan budaya.

\section{KAJIAN TEORI}

\section{A. Konsep Campur Kode}

Menurut Nababan (1986:32) "Campur bahasa merupakan mencampur dua atau lebih bahasa atau ragam bahasa dalam suatu tindakan bahasa (speech act atau discourse) tanpa ada sesuatu dalam situasi berbahasa itu yang menuntut pencampuran bahasa itu. Dalam keadaan yang demikian, hanya kesantaian penutur dan atau kebiasaannya yang dituruti." Berdasarkan peryataan tersebut dapat dinyatakan bahwa pencampuran bahasa tidak dipengaruhi oleh situasi berbahasa. Hal ini tidak sejalan dengan konsep campur kode yang ada dalam KBBI yang telah dikemukakan. Berdasarkan konsep Nababan mengenai campur kode, situasi tutur tidak berperan penting dalam mempengaruhi campur tutur. Justru kesantaian dan kebiasaanlah yang menentukan atau mempengaruhi seseorang dalam melakukan campur kode. Auzar dan Hermandra (2006:49) memperjelas bahwa campur kode adalah kegiatan mencampur dua bahasa atau lebih dalam suatu tindakan berbahasa.

Nababan (1986:32), ciri yang menonjol dalam peristiwa campur kode adalah kesantaian atau situasi informal. Jadi, campur kode umumnya terjadi saat berbicara santai, sedangkan pada situasi formal hal ini jarang sekali terjadi. Apabila dalam situasi formal terjadi campur kode, hal ini disebabkan tidak adanya istilah yang merajuk pada konsep yang dimaksud. Seperti telah disebutkan bahwa kode dapat berupa idiolek, dialek, register, tindak tutur, ragam, dan registrasi, maka unsur-unsur yang bercampur pun dapat berupa varian bahasa maupun bahasa itu sendiri.

Berdasarkan beberapa konsep mengenai campur bahasa dapat dapat dinyatakan membali bahwa campur kode merupakan penggunaan atau pemakaian dua bahasa atau lebih dalam situasi tertentu. Pemakaian dua bahasa atau lebih ini dapat berwujud kata, frase, klausa, ungkapan, dan idiom. Pemakaian hal-hal tersebut bertujuan menimbulkan gaya terhadap 
sebuah tuturan. Gaya atau cara yang digunakan dihubungkan dengan wujud campur kode, dan membatasi wujud campur kode tersebut terhadap situasi dan tidak lagi menduduki fungsi-fungsi sendiri.

\section{B. Tipe Campur Kode}

Menurut Suwito (1985) apabila terdapat dua bahasa atau lebih digunakan secara bergantian oleh penutur yang sama akan terjadi kontak bahasa. Sehingga terjadilah adanya campur kode dan alih kode tersebut. Dalam kondisi yang demikian maka terjadilah peristiwa saling kontak antara bahasa yang satu dengan bahasa yang lainnya (language contacts) dalam peristiwa komunikasi. Alih kode dan campur kode selalu melekat pada kehidupan sehari-hari terutama dalam percakapan dengan orang lain.

Berdasarkan sifatnya, alih kode dapat diklasifikasikan menjadi dua jenis yaitu, alih kode intern dan alih kode ekstern. Alih kode intern adalah alih kode yang terjadi antar bahasa-bahasa daerah dalam satu bahasa nasional, misalnya bahasa Jawa dan bahasa Madura. Alih kode ekstern merupakan alih kode yang terjadi antara bahasa asli dengan bahasa asing, misalnya bahasa Indonesia dengan bahasa Inggris.Hal ini sesuai dengan pendapat Soewito yang membedakan alih kode menjadi dua macam, yaitu alih kode intern dan alih kode ekstern.

Contoh inner code mixing : "Gua akan muterin lagunya Jason Mraz",

Contoh outer code mixing : "All right next insan muda"

\section{Teen Lit}

Secara etimologi, teenlit adalah akronim dari dua kata dalam bahasa Inggris, yaitu teenager ('belasan tahun') dan literature ('kesusastraan'). Mengacu pada pengertian tersebut, teenlit dapat diartikan sebagai bacaan yang bersegmentasi remaja (belasan tahun) yang mengangkat kehidupan remaja. Membicarakan teenlit tentu tak bisa lepas dari chicklit. Perbedaannya, chicklit diarahkan pada pasar gadis dewasa 17-26 tahun, sedangkan teenlit untuk kaum wanita yang lebih belia, seusia murid SMP-SMA (2005, www.suaramerdeka.com). Belakangan ini tak sulit untuk mengenali keduanya, sebab selalu tertera tulisan "Teenlit" atau "Chicklit" pada setiap sampul depannya.

Di Indonesia sendiri, teenlit tidaklah muncul secara tiba-tiba. Pada akhir tahun 1986 muncullah novel remaja ,Tangkaplah Daku kau Kujitak karya Hilman Hariwijaya. Novel remaja ini mengisahkan seorang remaja laki-laki SMA (bernama Lupus) dalam menjalani hariharinya.Tangkaplah Daku Kau Kujitak yang terbit pada bulan Desember 1986 dicetak, oleh PT. Gramedia, sebanyak 5.000 eksemplar yang habis dalam waktu kurang dari satu minggu dan dalam jangka waktu dua bulan terjual lebih dari 22.500 eksemplar (www.gramedia.com).

Nampaklah bahwa sebenarnya bentuk penulisan teenlit sudah dikenal di Indonesia, bahkan lebih dulu daripada Amerika Serikat, hanya pada waktu itu memang belum ada istilah untuk menyebutnya. Genre dalam teen lit yang cukup popular antara lain :

1. Chick lit, yang menceritakan seputar kehidupan wanita muda

2. Lad Lit, merupakan kebalikan dari chick lit dan menceritakan mengenai seputar kehidupan pemuda

\section{Macam-macam nilai pendidikan}

Adapun nilai-nilai pendidikan dalam novel sebagai berikut (Andika, 2010) :

a. Nilai Pendidikan Religius 
Religi merupakan suatu kesadaran yang menggejala secara mendalam dalam lubuk hati manusia sebagai human nature.

\section{b. Nilai Pendidikan Moral}

Moral merupakan sesuatu yang igin disampaikan pengarang kepada pembaca, merupakan makna yang terkandung dalam karya sastra, makna yang disaratkan lewat cerita.

\section{c. Nilai Pendidikan Sosial}

Kata "sosial" berarti hal-hal yang berkenaan dengan masyarakat/ kepentingan umum. Nilai sosial merupakan hikmah yang dapat diambil dari perilaku sosial dan tata cara hidup sosial.

d. Nilai Pendidikan Budaya

Nilai-nilai budaya menurut Rosyadi (1995:74) merupakan sesuatu yang dianggap baik dan berharga oleh suatu kelompok masyarakat atau suku bangsa yang belum tentu dipandang baik pula oleh kelompok masyarakat atau suku bangsa lain sebab nilai budaya membatasi dan memberikan karakteristik pada sutu masyarakat dan kebudayaannya.

\section{METODE PENELITIAN}

Penelitian ini dilakukan dengan menggunakan pendekatan kualitatif. Penggunaan pendekatan kualitatif dalam penelitian ini karena penelitian ini berkaitan dengan data penelitian yang tidak berupa angka tetapi berupa wacana (teks). Oleh karena itu, hasil penelitian dipaparkan dalam bentuk deskripsi datadata yang sudah dibatasi dalam rumusan masalah dan tujuan penelitian. Hasil penelitian ini dirumuskan setelah semua data dianalisis. Penulis memilih pendekatan deskriptif kualitatif karena penelitian ini dimaksudkan untuk mendeskripsikan aspek bahasa serta pendidikan dari novel teen lit yang menjadi subjek penelitian.
Yang menjadi subjek penelitian utama dalam penelitian ini adalah novel teen lit, yang difokuskan pada genre chick lit dan lad lit.

Chick lit :

1) "Aviredie" karya Alline - terbitan Mizan

2) "Grow up!" karya Sucia Ramadhani terbitan Mizan

3) "Pertama kalinya!" karya Sitta Karina dkk - terbitan Gramedi Pustaka Utama

4) "Oppa and I" karya Orizuka dan Lia Indra - terbitan Haru

Lad lit:

1) "Hidden agenda" karya Jacob Julian terbitan Bukune

2) "Marmut merah jambu" karya Raditya Dika - terbitan Gagas Media

3) "School of Chemistry" karya $\mathrm{Al}$ Dhimas- terbitan Gagas Media

Teknik analisis data antara lain :

1. Menganalisa penggunaan bahasa Inggris yang ada pada novel serta memastikan ketepatannya dari segi grammatical dan English expression.

2. Menganalisa nilai pedagogis dalam teen lit yang terdiri atas : nilai pendidikan religious, moral, budaya dan sosial.

3. Menarik kesimpulan.

\section{HASIL DAN PEMBAHASAN}

\section{A. Chick-lit "Oppa and I"}

Park Jae In dan Park Jae Kwon adalah sepasang saudara kembar, mereka tinggal terpisah karena orang tua mereka memutuskan untuk berpisah. Park Jae In ikut tinggal bersama ibunya di Jakarta sementara Park Jae Kwon tinggal di Korea bersama bapaknya. Setelah 5 tahun berlalu, kedua orang tuanya bersama kembali dan tinggal di Korea. Namun Park Jae In merasa keluarganya telah banyak 
berubah, sehingga ia menarik diri dan tidak ingin bergaul bersama keluarga dan teman-teman di sekolahnya. Lambat laun kepribadian Park Jae Kwon yang ceria meluluhkan hati saudara kembarnya, sehingga mereka berbaikan dan menjadi saudara yang lebih baik bagi satu sama lain.

\section{B. Chick-lit "Grow Up!"}

Fanny dan teman-temannya dalam ekskul "Magazine School" sedang sibuk mempersiapkan edisi baru untuk diterbitkan. Namun menjelang deadline, ternyata ada seseorang yang mencuri yang artikel-artikel yang sedang mereka kerjakan. Setelah diteliti lebih lanjut, akhirnya mereka menemukan bahwa pelakunya adalah Fanisa, seorang gadis yang iri pada ekskul "Magazine school". Setelah itu akhirnya mereka saling memaafkan dan ekskul "Magazine school" berjuang mengikuti lomba majalah sekolah level nasional. Dengan berbagai perjuangan dan dukungan dari para orang tua serta pihak guru di sekolah, ekskul "Magazine School" ini akhirnya memenangkan lomba sebagai juara pertama.

\section{Chick-lit "What friends are for"}

Berkisah mengenai 6 gadis yang bernama D'Alexandra Fransiska, Verlyna Ramos Presticya, Laura Lavigne, Ayra Grace, Clara Angelina dan Beferly Juliana yang berteman dan bersekolah di suatu asrama bernama Titania Boarding Secondary School dan menjalani kehidupan sebagai siswa dan saling bersahabat.

\section{Chick-lit "Pertama kalinya"}

Novel ini memiliki 8 cerpen terkait pengalaman pertama remaja. Ada cerita remaja yang selalu merasa egois dan mulai belajar memahami orang lain, ada cerita remaja yang belajar magang di perusahaan fashion, ada cerita remaja yang pertama kalinya mengadakan acara bakti sosial dan lainnya.

\section{E. Lad Lit "Hidden Agenda : bahaya di SMA Muda Bakti"}

SMA Muda Bakti mengalami keterkejutan setelah menemukan adanya laporan penyimpangan keuangan dalam dana OSIS mereka. Hal tersebut menyebabkan banyak kegiatan esktra kurikuler yang tidak berjalan dengan baik karena dana dibekukan oleh sekolah. Jana berusaha menyelidiki hal ini agar kegiatan ekstra kurikuler sekolah dapat berjalan dengan lancar seperti biasa.

\section{F. Lad Lit "Marmut Merah Jambu"}

Raditya Dika, lebih dikenal sebagai Dika menceritakan berbagai bentuk kisah cinta dari kisah cinta paling sederhana saat dia masih SD hingga kisah cinta paling murni yaitu cinta antar anggota keluarga.

\section{G. Lad Lit "School Chemistry"}

Marsha adalah seorang adik yang berada dalam bayang-bayang kakaknya Alisha yang cerdas. Alisha pandai di semua bidang kecuali kimia. Hal itu menyebabkan Marsha berjuang keras mempelajari kimia agar ia bisa lepas dari bayang-bayang kakaknya tersebut. Dengan keempat sahabatnya di sekolah, ia berjuang agar bisa memasuki tim kimia dan berteman baik dengan seluruh teman di sekolahnya.

\section{H. Hasil Wawancara}

Berikut ini adalah hasil wawancara mengenai novel teen-lit dengan orang tua, guru dan siswa.

Pendapat dari orang tua :

1. Jaman dulu karya anak dan remaja masih terbatas, diantaranya : lima sekawan, sapta siaga, gadis paling badung di sekolah, serial Nina dll.

2. Mengikuti perkembangan jaman, yang paling berpengaruh dalam 
perkembangan teen-lit adalah masuknya komik-komik Jepang seperti serial cantik

3. Bagi orang tua yang memiliki anak, maka novel terbitan Mizan seperti KKPK, Pink Berry dan Fantasteen bisa menjadi pilihan karena ceritanya bagus, tidak mengarah pada unsur pornografi serta banyaknya percakapan bahasa Inggris dalam novel tersebut.

4. Sesuai dengan jiwa anak yang memiliki tingkat identifikasi yang tinggi, maka unsur-unsur bahasa Inggris dalam novel-novel teen-lit cepat terserap oleh anak sehingga mereka umumnya "meniru" dalam percakapan sehari-hari, termasuk menuliskannya dalam media sosial.

Pendapat dari guru :

1. Untuk pelajaran bahasa Inggris, metode yang menarik untuk mulai memperkenalkan Bahasa Inggris adalah dengan kegiatan story telling.

2. Untuk para siswa, buku yang biasanya dibahas $90 \%$ adalah buku-buku kegemaran mereka yaitu buku KKPK, PinkBerry dan Fantasteen. Mereka menyukai novel yang bernuansa horror sehingga lebih senang dalam membacanya.

3. Perpustakaan sekolah juga amat disarankan untuk menyediakan novelnovel sejenis sehingga merangsang daya baca siswa.

4. Untuk menambah vocabulary siswa, kutipan dan ungkapan bahasa Inggris dalam novel bisa dijadikan sebagai pelajaran.

5. Untuk menambah kemampuan siswa dalam bidang tulis-menulis, novelnovel teen-lit ini bisa dijadikan rujukan selain tugas menulis jurnal dan lainnya.

\begin{tabular}{|l|c|c|c|c|c|}
\hline No & Judul & \multicolumn{2}{|c|}{ Jumlah kata } & Kandungan aspek & Catatan tambahan \\
\hline 1 & "Oppa and I" & $\begin{array}{r}\text { outer code } \\
\text { mixing dan } \\
1 \text { inner code }\end{array}$ & $\begin{array}{c}\text { Moral, sosial dan } \\
\text { budaya }\end{array}$ & $\begin{array}{c}\text { Mengandung banyak } \\
\text { unsur kebudayaan } \\
\text { dan bahasa Korea. }\end{array}$ \\
\hline
\end{tabular}

\section{Pendapat dari siswa:}

1. Yang menjadi pilihan dan pertimbangan utama mereka dalam memilih suatu buku untuk dibaca adalah buku yang memiliki gambar dan warna yang cerah.

2. Buku yang menjadi pilihan adalah buku yang tidak terlalu tebal dengan ukuran font yang besar. Bila terlalu tebal, gambar sedikit dan ukuran font kecil biasanya tidak menimbulkan keinginan untuk membaca.

3. Novel teen-lit (terutama KKPK) adalah favorit bagi para siswa karena ceritanya menarik, lucu dan katakatanya mudah dimengerti, untuk genre tema novel lain misalnya Fantasteen dan Pinkberry karena ceritanya lebih beragam, dan banyak dibumbui unsur horor dan misteri. Terutama bila ceritanya mengenai sekolah, maka para siswa merasa lebih cocok dan sesuai dengan keseharian mereka.

4. Untuk unsur bahasa Inggris, para siswa banyak belajar dari novel-novel tersebut. Untuk kata-kata yang pendek mereka cukup paham, namun bila cukup panjang maka mereka akan mempelajarinya menggunaka kamus. Dan bila sudah paham, maka mereka akan menggunakannya dalam kehidupan sehari-hari atau menuliskannya di media sosial seperti Facebook dan Instagram.

\section{KESIMPULAN}

Penelitian ini bermaksud untuk mengetahui jumlah dan jenis kandungan bahasa Inggris yang terdapat di dalamnya, serta mengetahui kandungan aspek pedagogis yang terkandung dalam novelnovel ini, berikut penemuan yang didapat: 


\begin{tabular}{|c|c|c|c|c|}
\hline No & Judul & Jumlah kata & Kandungan aspek & Catatan tambahan \\
\hline & & mixing & & $\begin{array}{lr}\text { Cocok bagi para } \\
\text { remaja } & \text { yang } \\
\text { menggemari } & \\
\text { kebudayaan } & \text { Korea. } \\
\text { Namun r unsur } \\
\text { bahasa } r \text { Inggris } \\
\text { tidak ranyak } \\
\text { ditemukan. }\end{array}$ \\
\hline 2 & "Grow up!" & $29 \begin{array}{l}\text { Outer code } \\
\text { mixing dan } \\
34 \text { inner } \\
\text { code mixing }\end{array}$ & $\begin{array}{cr}\text { Religius, } & \text { moral, } \\
\begin{array}{l}\text { sosial } \\
\text { budaya }\end{array} & \text { dan }\end{array}$ & $\begin{array}{l}\text { Dari segi cerita dan } \\
\text { aspek pedagogis, } \\
\text { cukup } \\
\text { Banyak } \\
\text { menceritakan } \\
\text { mengenai proses } \\
\text { pembuatan majalah } \\
\text { sekolah. }\end{array}$ \\
\hline 3 & $\begin{array}{l}\text { "What friends } \\
\text { are for" }\end{array}$ & $\begin{array}{l}53 \text { outer code } \\
\text { mixing dan } \\
28 \text { inner } \\
\text { code mixing }\end{array}$ & $\begin{array}{l}\text { Sosial, budaya dan } \\
\text { moral }\end{array}$ & $\begin{array}{lr}\begin{array}{cr}\text { Mengandung } \\
\text { banyak }\end{array} & \text { cukup } \\
\text { Bahasa } & \text { Inggris } \\
\text { serta } & \text { kebudayaan } \\
\text { Barat. } & \text { Banyak } \\
\text { ungkapan } & \text { Bahasa } \\
\text { Ingrisnya } & \text { yang } \\
\text { kurang tepat, serta } \\
\text { mengandung unsur } \\
\text { materialisme. }\end{array}$ \\
\hline 4 & $\begin{array}{l}\text { "Pertama } \\
\text { kalinya!" }\end{array}$ & 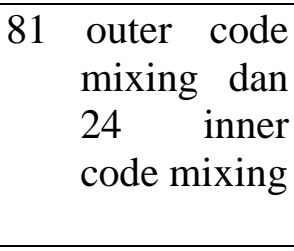 & $\begin{array}{l}\text { Sosial, budaya dan } \\
\text { moral }\end{array}$ & \begin{tabular}{cr} 
Unsur bahasa & Inggris \\
yang ditemukan \\
sangat banyak \\
dengan aspek cerita \\
\multicolumn{2}{c}{ yang beragam. } \\
\end{tabular} \\
\hline 5 & "Hidden agenda" & $\begin{array}{l}\text { outer code } \\
\text { mixing dan } \\
17 \text { inner } \\
\text { code mixing }\end{array}$ & Sosial dan moral & $\begin{array}{l}\text { Bisa dijadikan bahan } \\
\text { ajar } \\
\text { penyalahgunaan } \\
\text { narkoba. }\end{array}$ \\
\hline 6 & $\begin{array}{l}\text { "Marmut merah } \\
\text { jambu" }\end{array}$ & $\begin{array}{l}35 \text { outer code } \\
\text { mixing dan } \\
33 \text { inner } \\
\text { code mixing }\end{array}$ & $\begin{array}{l}\text { Moral, religi, sosial } \\
\text { dan budaya }\end{array}$ & $\begin{array}{cr}\text { Memiliki keseluruhan } \\
\text { komponen } & \text { aspek } \\
\text { pedagogis. } & \text { Unsur } \\
\text { bahasa } & \text { Inggris } \\
\text { tidak terlalu banyak } & \text { ditemukan, namun } \\
\text { ceritanya } & \text { dengan } \\
\text { genre } & \text { komedi } \\
\text { cukup menghibur. }\end{array}$ \\
\hline 7 & $\begin{array}{l}\text { "School } \\
\text { chemistry" }\end{array}$ & $\begin{array}{l}103 \text { outer code } \\
\text { mixing }\end{array}$ & $\begin{array}{l}\text { Moral, sosial dan } \\
\text { budaya }\end{array}$ & $\begin{array}{cr}\text { Mengandung } & \text { unsur } \\
\text { bahasa } & \text { Inggris } \\
\text { yang } & \text { paling }\end{array}$ \\
\hline
\end{tabular}




\begin{tabular}{|c|c|c|c|c|}
\hline No & Judul & Jumlah kata & Kandungan aspek & Catatan tambahan \\
\hline & & & & banyak. \\
\hline
\end{tabular}


Teen-lit yang ditulis umumnya memiliki cerita yang cukup baik dan bisa dijadikan panduan sebagai pegangan dalam pembelajaran maupun cerita sehari-hari dengan ungkapan bahasa Inggris yang cukup banyak ditemukan, namun tergantung kepada genre, jenis dan cerita yang ditulis. Apakah berdasarkan tema Korea, tema keseharian remaja pada umumnya atau tema fiksi lainnya. Sebagai bahan pendamping mata kuliah translating maka ungkapan bahasa Inggris serta ekspresi dan ujaran bahasa Inggris yang terdapat dalam novel teen-lit bisa digunakan sebagai bahan ajar untuk diterjemahkan kedalam Bahasa Ibu. Dan sebagai bahan pendamping mata kuliah literature , novel teen-lit ini terdiri atas berbagai bentuk dan jenis cerita yang bisa dianalisis baik dari segi kebahasaan, intrinsik maupun pesan moralnya sehingga aspek pedagogis yang terdapat dalam cerita bisa dianalisis dan menjadi wacana diskusi di dalam kegiatan belajar mengajar.

\section{DAFTAR PUSTAKA}

Alwi, Hasan dkk. 2005. Kamus besar Bahasa Indonesia. Jakarta: Balai Pustaka.

Andika,Nugroho.2010.Analisis nilai-nilai pendidikan novel Sang Pemimpi.Universitas Sebelas Maret

Anonim.2005. Teen Lit serial ala Sitta Karrina,

http://sembarang.com/2005/09/26/teenl it-serial-ala-sitta-karina/.29 Januari 2016

Annida Online.Alumni KKPK melaju ke lini Pinkberry. (http://annidaonline.com/alumni-kkpk-melaju-ke-linibaru-pink-berry-club.html)

Anonim.2008.Fenomena Teen Lit.https://houseofreadinc.wordpress.co $\mathrm{m} / 2008 / 06 / 26 /$ fenomena-teenlit/.29

Januari 2016

Anonim.2016.Fenomena buku novel remaja teenlit.

http://www.binasyifa.com/279/51/27/fe nomena-buku-novel-remajateenlit.htm.29 Januari 2016

Aziez,Furqonul.2010.Menganalisis fiksi.Bogor:Ghalia Indonesia

Kata.2012.Analisis nilai-nilai pendidikan novel sang pemimpi.https://serdadukataku.wordpre ss.com/2012/12/02/analisis-nilai-nilaipendidikan-novel-sang-pemimpi/.29 Januari 2016

Kurnia,RS.2012.Teen Lit sebagai cermin budaya remaja perkotaan masa kini. kini.http://pelitaku.sabda.org/teenlit_se bagai_cermin_budaya_remaja_perkota an_masa_kini.29 Januari 2016

Kustriyono,Erwan.(----).Alih kode dan campur kode percakapan mahasioswa di perpustakaan Universitas Pekalongan. PBSI FKIP Universitas Pekalongan

Maulidini, Ratna.2007.Campur kode sebagai strategi komunikasi Customer service: Studi Kasus Nokia Care Centre Bimasakti Semarang .(Skripsi).Tidak dipublikasikan. Semarang: Fakultas Sastra Universitas Diponegoro.

Nababan, PWJ. 1986. Sosiolinguistik: Suatu Pengantar. Jakarta: PT. Gramedia.

Rohmani,Siti.(2013).Analisis alih kode dan campur kode pada novel Negeri 5 Menara karya Ahmad Fuadi.Surakarta. BASASTRA Jurnal Penelitian Bahasa, Sastra Indonesia dan Pengajarannya. Volume 2 No 1 April 2013 ISSN 12302-6405 